\title{
Notch Prosensory Effects in the Mammalian Cochlea Are Partially Mediated by Fgf20
}

\author{
Vidhya Munnamalai, Toshinori Hayashi, and Olivia Bermingham-McDonogh \\ Department of Biological Structure and Institute for Stem Cell and Regenerative Medicine, University of Washington, Seattle, Washington 98195
}

Hearing loss is becoming an increasingly prevalent problem affecting more than 250 million people worldwide. During development, fibroblast growth factors (FGFs) are required for inner ear development as well as hair cell formation in the mammalian cochlea and thus make attractive therapeutic candidates for the regeneration of sensory cells. Previous findings showed that $F g f r 1$ conditional knock out mice exhibited hair cell and support cell formation defects. Immunoblocking with Fgf20 antibody in vitro produced a similar phenotype. While hair cell differentiation in mice starts at embryonic day (E)14.5, beginning with the inner hair cells, $F g f 20$ expression precedes hair cell differentiation at E13.5 in the cochlea. This suggests a potential role for Fgf20 in priming the sensory epithelium for hair cell formation. Treatment of explants with a gamma-secretase inhibitor, DAPT, decreased Fgf $20 \mathrm{mRNA}$, suggesting that Notch is upstream of Fgf20. Notch signaling also plays an early role in prosensory formation during cochlear development. In this report we show that during development, Notch-mediated regulation of prosensory formation in the cochlea occurs via Fgf20. Addition of exogenous FGF20 compensated for the block in Notch signaling and rescued Sox2, a prosensory marker, and Gfil, an early hair cell marker in explant cultures. We hypothesized that Fgf20 plays a role in specification, amplification, or maintenance of Sox 2 expression in prosensory progenitors of the developing mammalian cochlea.

\section{Introduction}

The development of the cochlea has received considerable attention in recent years as a model system for studies of cell interactions in patterning, sensory repair, and regeneration. Induction of the sensory epithelium within the mouse cochlear duct occurs around embryonic day (E) 11. The prosensory progenitors within the sensory domain of the developing cochlea express Sox2. Hair cells begin to differentiate around E14.5, starting with the inner hair cells followed by the outer hair cells from base to apex and medial to lateral (Ruben, 1967; Chen and Segil, 1999). By E17, hair cells are organized into the typical one row of inner hair cells and three rows of outer hair cells, with all hair cells surrounded by support cells (Ruben, 1967; Sher, 1971; Lim and Anniko, 1985).

Notch signaling plays two established roles in inner ear development: prosensory specification (Kiernan et al., 2006; Hayashi et al., 2008a) and lateral inhibition (Zine et al., 2001; Kiernan et

Received May 9, 2012; revised July 17, 2012; accepted July 20, 2012.

Author contributions: V.M., T.H., and 0.B-McD. designed research; V.M. and T.H. performed research; V.M., T.H., and O.B-MCD. analyzed data; V.M. and O.B-MCD. wrote the paper.

This research is supported by National Institutes of Health/ National Institute on Deafness and Other Communication Disorders (NIH/NIDCD) Grants DC005953 and DC009991 (to 0.B-MCD.), NIH/NIDCD Research Core Center Grant P30DC004661, and the Lynn and Mike Garvey Cell Imaging Laboratory at the Institute for Stem Cell and Regenerative Medicine, University of Washington, Seattle, WA. We thank Linda Robinson for help with animal husbandry and past and present members of the Reh and Bermingham-McDonogh laboratories for support and advice. We thank Drs. J. Brzezinski, A. La Torre, and T. Reh for comments on this manuscript. We also thank Dr. H. Bellen for the antibody to Gfi1.

Correspondence should be addressed to Dr. Olivia Bermingham-McDonogh, Department of Biological Structure, Institute for Stem Cell and Regenerative Medicine, Box 358056, 815 Mercer Street, Seattle, WA 98195. E-mail: oliviab@u.washington.edu.

T. Hayashi's present address: Division of Bio-signaling, School of Life Science, Faculty of Medicine, Tottori University, 86 Nishi-machi, Yonago City, Tottori Prefecture, 683-8503 Japan.

DOI:10.1523/JNEUROSCI.2250-12.2012

Copyright $\odot 2012$ the authors $\quad 0270-6474 / 12 / 3212876-09 \$ 15.00 / 0$ al., 2005b; Brooker et al., 2006). Daudet and colleagues first suggested an early role for Notch in inner ear development in the chick embryo (Daudet and Lewis, 2005; Daudet et al., 2007). Overexpression of the Notch intracellular domain (NICD) outside the sensory epithelia of the inner ear induced ectopic hair cell formation (Daudet and Lewis, 2005). In mouse Jag1 loss-offunction mutants, the sensory epithelium development was compromised (Kiernan et al., 2001). Notch inhibition, using a gamma-secretase inhibitor, DAPT, on E12.5 cochlea explants, decreased prosensory formation in vitro (Hayashi et al., 2008a). More recently, Rbpj conditional knockout (cKO) mice also showed decreased Sox 2 and $p 27^{k i p 1}$ expression, which are early markers of the prosensory domain (Yamamoto et al., 2011). Furthermore, ectopic expression of NICD induced extrasensory patches in the nonsensory areas of the mouse inner ear (Hartman et al., 2010; Pan et al., 2010).

Similar to Notch, fibroblast growth factor (FGF) signaling has also been shown to be important for sensory cell formation in the cochlea. The Fgfrl cKO mice showed a decrease in hair cells and support cells (Pirvola et al., 2002). Inhibition of FGF receptors using SU5402 on cochlear explants also showed a similar impact on hair cell and support cell formation. Immunoblocking with Fgf20 antibody also decreased hair cell formation, suggesting that Fgf20 is the likely ligand activating Fgfr 1, which is the only FGF receptor that is expressed in the sensory domain at this early stage of development (Hayashi et al., 2008b, 2010). These results demonstrated that Fgf20/Fgfr1 signaling is required for the prosensory phase of development.

Sox2 plays a critical role in prosensory specification and is required for sensory epithelium formation (Kiernan et al., 2005a). Interestingly, both Notch inhibition and Fgfr inhibition decreased 
E12.5
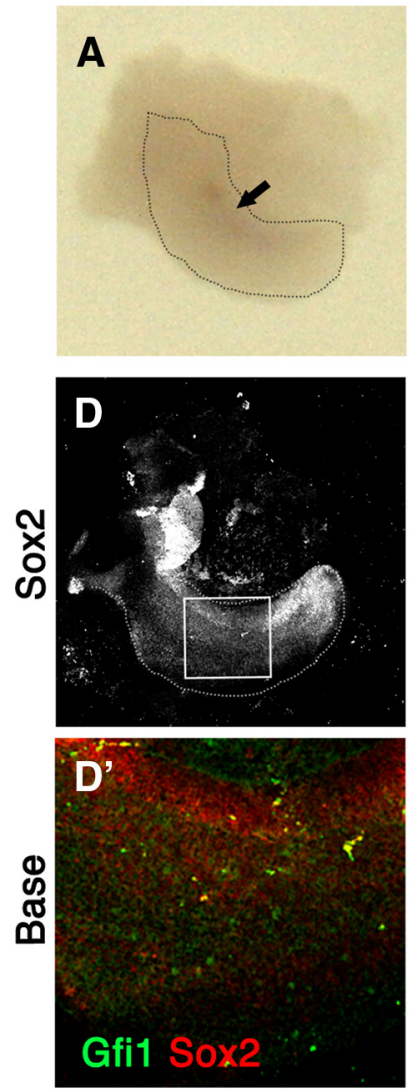

E13.5
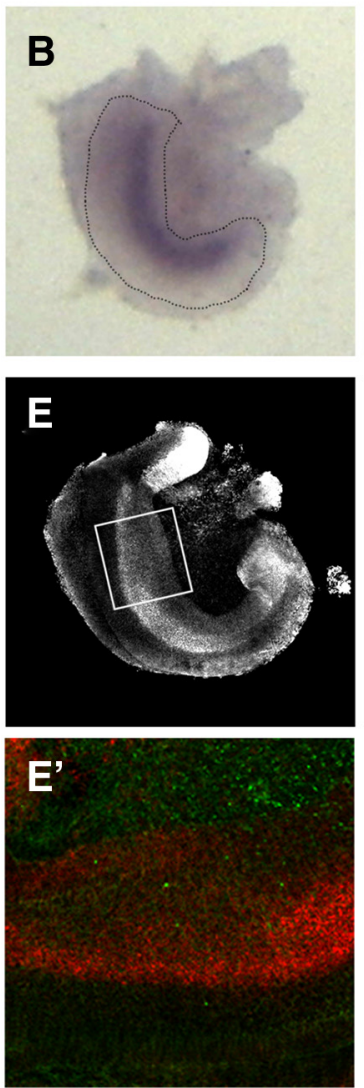

E14.5
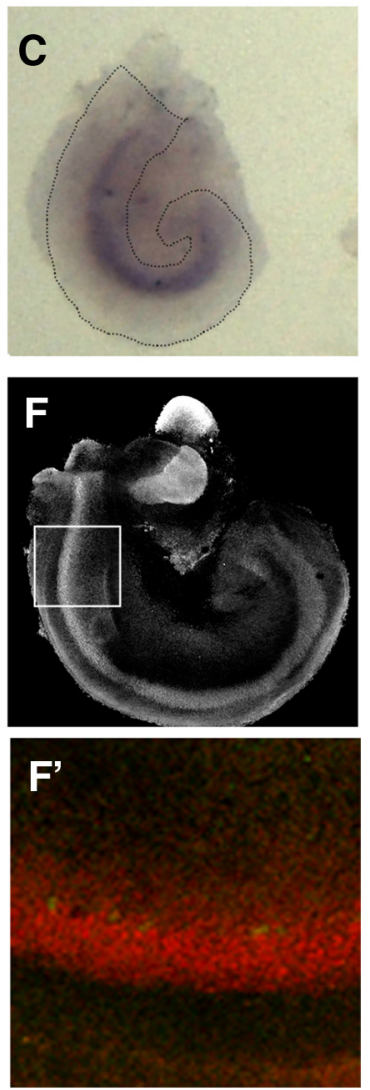

G

Embryonic Day (Age of explant)

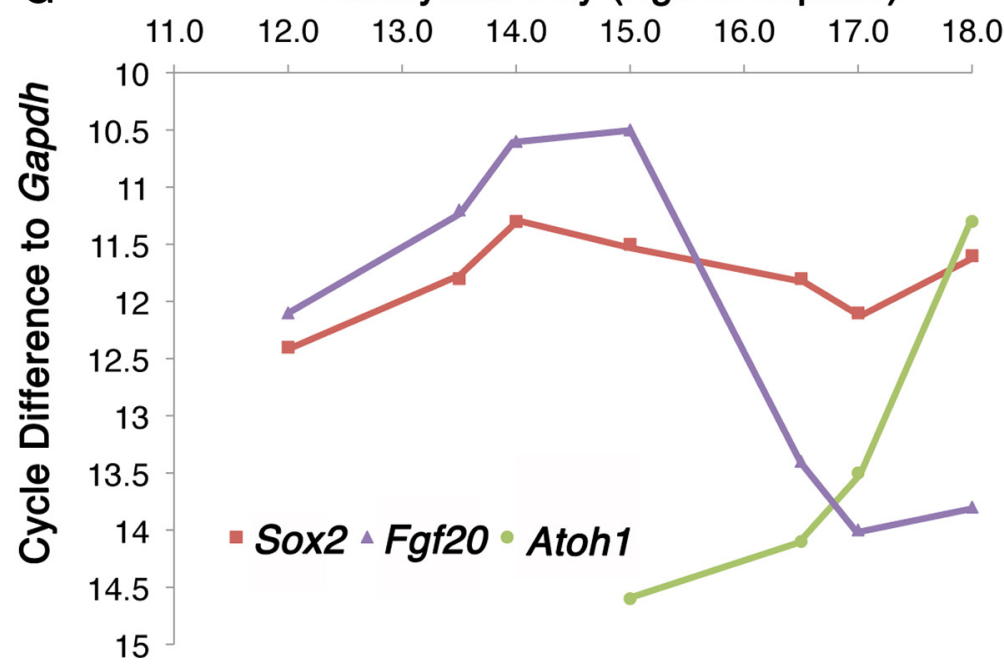

Figure 1. The transient expression of Fgf20 occurs before sensory cell formation. $\boldsymbol{A}-\boldsymbol{C}$, Explants probed for Fgf 20 mRNA shows very faint expression of $\mathrm{Fgf20}$ at E12.5 that gradually increases until E14.5. Fgf20 is very faintly expressed at E12.5 (A) and strongly upregulated in E13.5 (B) and E14.5 explants (C). D-F Immunolabeling of Sox2 in E12.5-E14.5 explants also shows a gradual increase in Sox2 levels in the developing cochlea. Boxed areas in $\boldsymbol{D}-\boldsymbol{F}$ are shown in higher magnification in $\boldsymbol{D}^{\prime}-\boldsymbol{F}^{\prime}$ with Sox2 (red) and Gfi1 (green) labeling at E12.5 to E14.5. G, RT-PCR analysis of cochlear tissue from various embryonic ages shows the relative expression of Sox2, Fgf20, and Atoh1.

Sox2 expression in the cochlea (Hayashi et al., 2008a,b; Millimaki et al., 2010). We hypothesized that there is a link between Notch and Fgf20. We have investigated this hypothesis using an explant culture system. We report that upon DAPT-mediated prosensory inhibition, exogenous FGF20 rescued Sox2 expression. In addition, hair cells were also rescued. The rescue of Sox 2 suggests that the primary function of Fgf20 is to increase or maintain Sox 2 expression in prosensory progenitors.

\section{Materials and Methods}

Mice. Timed-pregnant Swiss-Webster mice were purchased from Harlan and housed in the Department of Comparative Medicine at South Lake Union (Seattle, WA). All procedures were carried out in accordance with Institutional Animal Care and Use Committee of the University of Washington (Seattle, WA) and NIH guidelines. The Theiler staging system (Theiler, 1989) was used to stage embryos. We did not determine the gender of the embryos.

Organotypic culture of embryonic cochleas. Cochlear explants of embryonic day (E) 13.5 and E12.5 mice were dissected and cultured as described previously (Hayashi et al., 2008b). The surrounding capsule tissue was enzymatically digested with $0.1 \%$ dispase and $0.1 \%$ collagenase for $5 \mathrm{~min}$ at room temperature and mechanically separated using fine forceps. With fine forceps, the roofs of the cochlear ducts were removed up to the apex to allow maximum exposure to FGFs as reported previously (Hayashi et al., 2008b). Cochlear explants were cultured at the liquid gas interphase on collagen/Matrigel-coated cell culture inserts: 5 days for E13.5 explants and 6 days for E12.5 explants. Notch signaling was inhibited with $30 \mu \mathrm{M} \mathrm{N}$-[N-(3,5-difluorophenacetyl)-Lalanyl]-S-phenylglycine $t$-butyl ester (DAPT) (Peptide International), while control explants included DMSO vehicle. For the FGF20 rescue condition, (500 ng/ ml, PeproTech), cochleae were cultured in modified DMEM: F12 media containing DAPT and human recombinant FGF20. FGF9 was prepared in a similar manner ( $1 \mu \mathrm{g} / \mathrm{ml}$, PeproTech). The media was supplemented with $2 \mu \mathrm{g} / \mathrm{ml}$ heparin to enhance FGF20-receptor binding. Media changes were performed daily.

Immunohistochemistry. Culture membranes containing explants were cut out of inserts and fixed in cold $4 \%$ formaldehyde in PBS $/ 0.5 \%$ Triton X-100 for $15 \mathrm{~min}$. Explants were then washed three times, 20 min with PBS/0.1\% Triton $\mathrm{X}-100$ followed by blocking for $30 \mathrm{~min}$ in $10 \%$ FBS/PBS/0.1\% Triton X-100. Primary antibody incubation in blocking solution was carried out overnight at $4^{\circ} \mathrm{C}$ followed by 2 hour-long washes and an overnight wash. Secondary antibodies were incubated for $3 \mathrm{~h}$ at room temperature followed by several hourlong and overnight washes with PBS/0.1\% Triton X-100. Samples were mounted with Fluoromount G (Southern Biotech). The following primary antibodies were used: antirabbit Myo-6 (1:1000) (Proteus), anti-rabbit Prox1 (1:1000) (Millipore), anti-goat Sox2 (1: 1000) (Santa Cruz Biotechnology), and antiguinea pig Gfil (1:1000) (gift from Hugo Bellen, Baylor College of Medicine, Houston, TX). Secondary antibodies used were donkey anti-goat Alexa Fluor 568, donkey anti-rabbit Alexa Fluor 633, and donkey anti-guinea pig Alexa Fluor 488 (Invitrogen).

Quantitative RT-PCR. A pool of four cochleas per condition, no FGF20 (DMSO control), DAPT alone, and FGF20 with DAPT, were cultured and homogenized in $250 \mu \mathrm{l}$ of TRIzol (Invitrogen) followed by phenol chloro- 

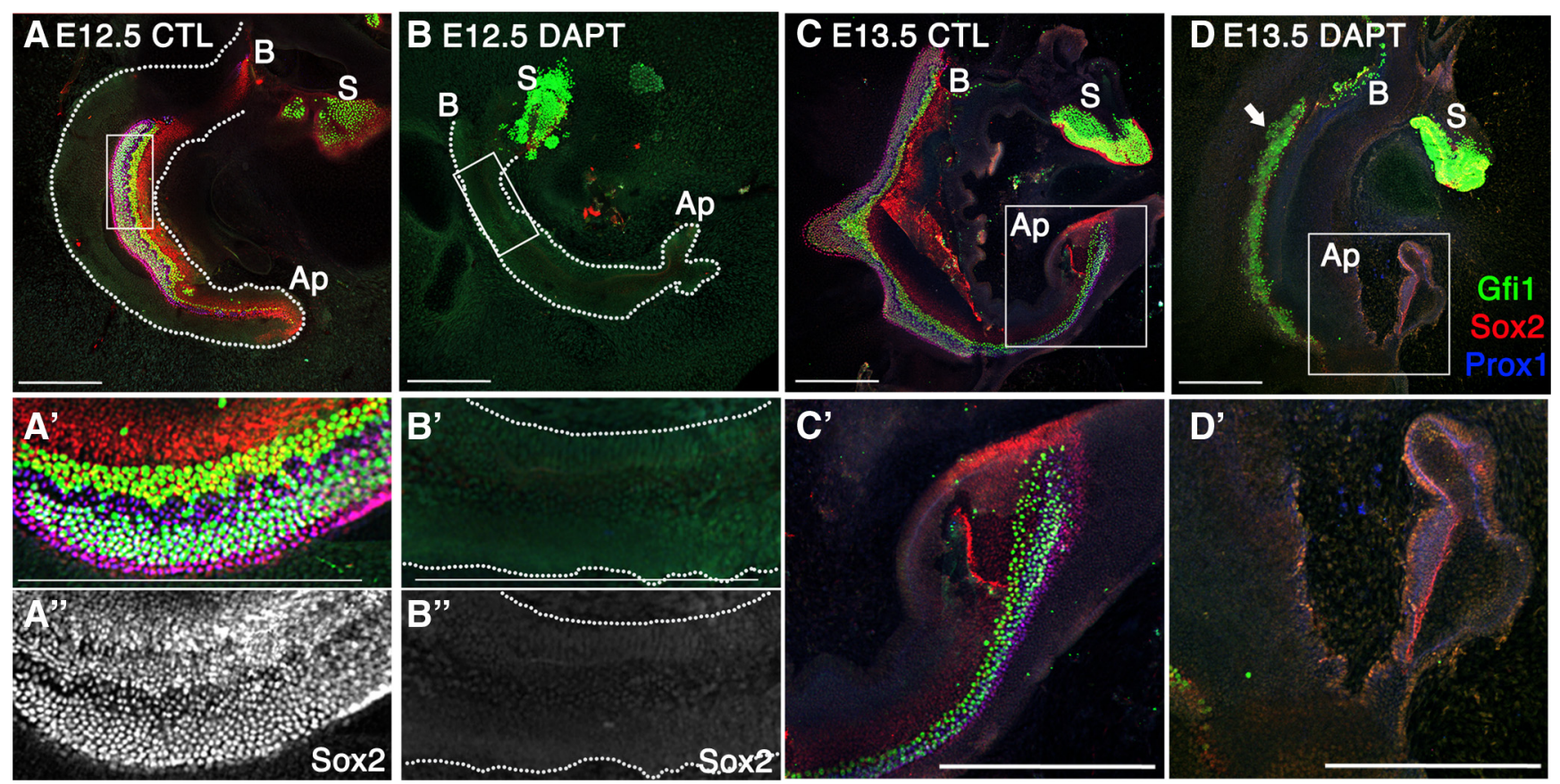

Figure 2. Notch has multiple roles during cochlear development. All explants were labeled with Gfi1 (green), Sox2 (red), and Prox1 (blue). $\boldsymbol{A}, \boldsymbol{B}$, Notch inhibition with DAPT of E12.5 explants shows a disruption in the formation of the sensory epithelium. $\boldsymbol{A}^{\prime}, \boldsymbol{B}^{\prime}$, Higher magnification of boxed inset in $\boldsymbol{A}$ and $\boldsymbol{B}$, respectively. $\boldsymbol{A}^{\prime \prime}, \boldsymbol{B}^{\prime \prime}$, Same as $\boldsymbol{A}^{\prime}$ and $\boldsymbol{B}^{\prime}$, respectively, showing Sox2 labeling alone. $C$, E13.5 control explants. $C^{\prime}$, Higher magnification of boxed inset in $C$. D, DAPT treatment at E13.5 shows dual effects: blocking lateral inhibition in the base to mid-base region (arrow) and prosensory inhibition at the apex ( $\left.\boldsymbol{D}^{\prime}\right)$. S, Saccule; $B$, base; Ap, apex. Scale bars, $200 \mu \mathrm{m}$.

form extraction, DNase treatment, and reversetranscription into cDNA by Superscript III reverse transcriptase (Invitrogen). Reactions were carried out using the following primer sets: FGF-20, Sox2, and Math1. RT-quantitative PCR (qPCR) analysis was performed on the ABI 7900 384- and 96-well block with TaqMan Low Density Array. Three biological experiments were carried out for each condition. In all samples, cycle differences were calculated to Gapdh. In DAPT- and FGF20-treated samples, a cutoff at 38 cycles was set for calculating cycle differences to Gapdh. Any transcript amplified at cycle 38 was considered as not being expressed.

For RT-qPCR of various genes across different ages, large pools of 14-22 cochleas per time point were collected and synthesized into cDNA and analyzed for Atoh1, Sox2, and Fgf20 primers. Cycle differences from Gapdh were calculated and reversed on the $y$-axis to show relative trends with respect to other genes. In all RT-qPCR experiments, the saccule was removed to measure gene expression in the cochlea alone. Primers used were as follows: $\mathrm{Fg} 20$, forward $5^{\prime}$-ccttgggatgaatg acaaagga- $3^{\prime}$ and reverse- $5^{\prime}$-cgacccgtgtttccatgttt$3^{\prime}$; Sox2, forward $5^{\prime}$-gcggagtggaaacttttgtcc- $3^{\prime}$ and reverse $5^{\prime}$-cgggaagcgtgtacttatcctt- $3^{\prime}$; Atoh 1 , forward $5^{\prime}$-tcccgtccttcaacaacgac- $3^{\prime}$ and reverse $5^{\prime}$-ctctccgacattgggagtctg- $3^{\prime}$.

Imaging. Z-stacks were acquired on a Nikon Eclipse Ti confocal laser microscope system at the Garvey Cell Imaging Lab (University of Washington, Seattle, WA). Maximum projection images were rendered from z-stacks to quantify hair cells numbers and regions of interest in the cochlear ducts using the NIS-Elements software.

In situ hybridization. Cochlear explants were fixed in $7 \%$ formaldehyde followed by dehydration in an ethanol-DEPC series of 50\%, 70\%, $90 \%, 95 \%$, and three $100 \%$ washes. Explants were subjected to two 5 min xylene washes and three final washes with $100 \%$ ethanol. Tissues

\section{Fgf20 in-situ}
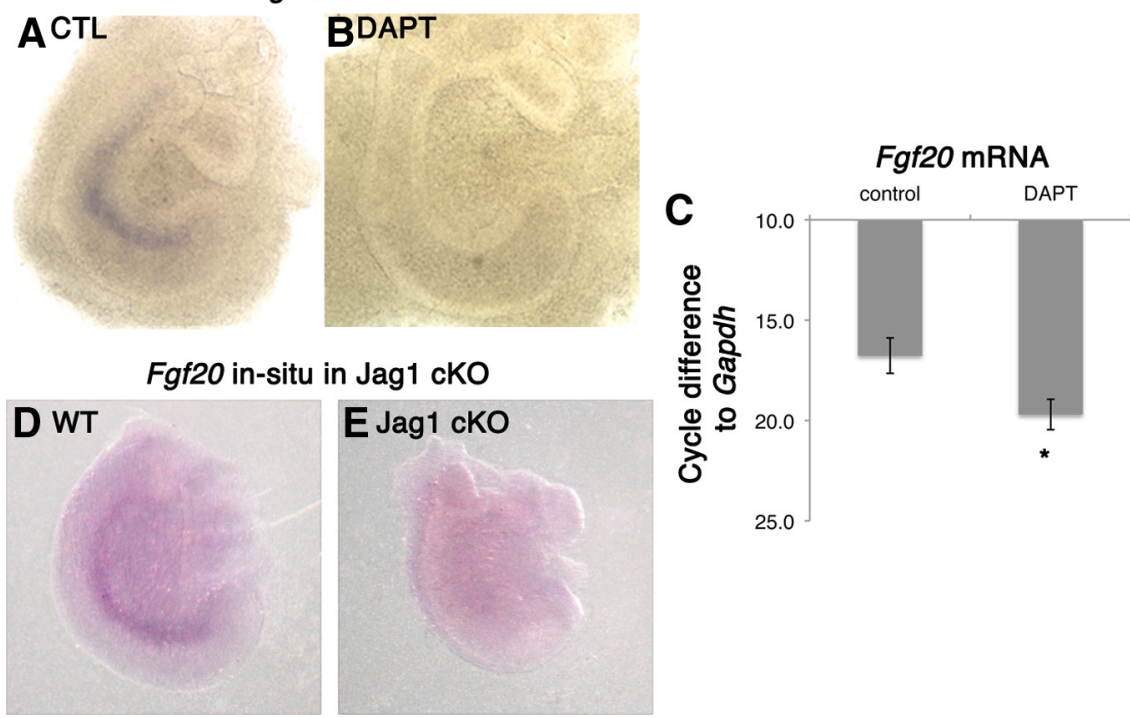

Figure 3. Notch regulates Fgf20 expression. $A, B$ E12.5 +1 DIV explants in the absence and presence of DAPT were probed for Fgf20 mRNA. DAPT treatment decreased Fgf20 mRNA. C, Quantitative PCR analysis on E12.5 + 3 DIV explants confirms that DAPT treatment decreased Fgf20 expression. One-way ANOVA for correlated samples show statistical significance; ${ }^{*} p<0.05, n=3$ experiments. Fgf20 mRNA was probed by in situ hybridization in Jag1 conditional knockouts. D, E, Wild-type embryos showed Fgf20 expression (D) and no Fgf20 expression in Jag 7 knockout littermates $(\boldsymbol{E})$.

were incubated at $70^{\circ} \mathrm{C}$ for an hour in hybridization mix, followed by 0.2 $\mathrm{mg} / \mathrm{ml}$ of digoxigenin (DIG)-labeled Fgf20 RNA probe for 2 days. DIGlabeled probes were prepared according to the manufacturer's protocol (Roche) After sufficient washing, tissues were incubated overnight at $4^{\circ} \mathrm{C}$ with anti-DIG-AP antibody (1:2000) (Roche) (Hayashi et al., 2008b). The in situs were developed with NBT/BCIP solution and postfixed with $4 \%$ formaldehyde $/ 0.1 \%$ Triton X-100 in PBS.

Jag1 conditional knock out mutants. To inactivate Jag1 function in the inner ear, heterozygous Foxg1-Cre mice (The Jackson Laboratory) were 

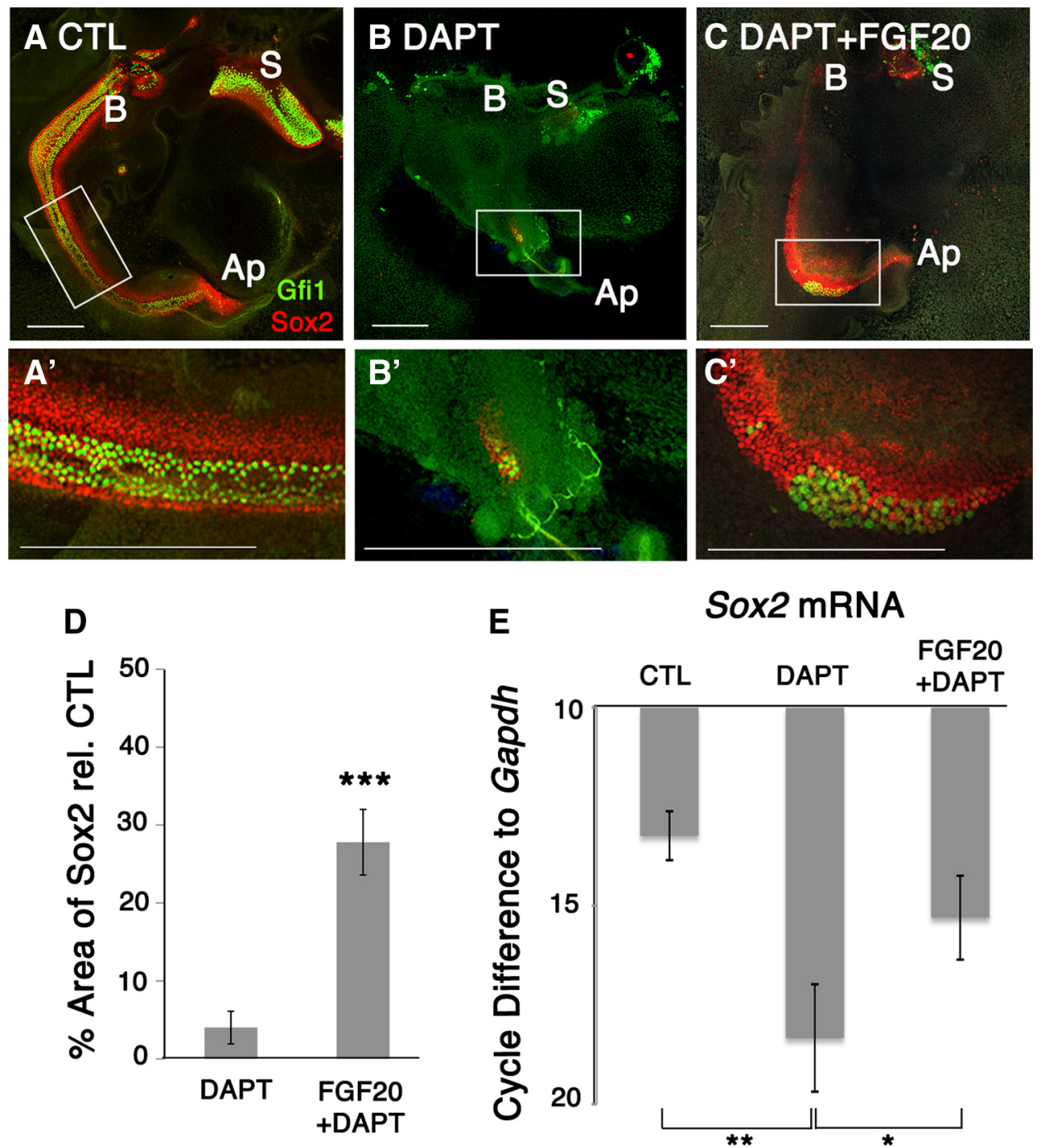

Figure 4. Fgf20 rescued Notch-inhibited prosensory precursors at E12.5 +6 DIV. $A, A^{\prime}$, Control explants show clear development of both Gfi1 ${ }^{+}$and Sox2 ${ }^{+}$sensory cells. $\boldsymbol{B}$, DAPT treatment of E12.5 explants for 6 DIV affects sensory epithelium development. $\boldsymbol{B}^{\prime}$, Both Gfi ${ }^{+}$and Sox2 ${ }^{+}$cells were affected. $\boldsymbol{C}$, Fgf20 in the presence of DAPT rescued Sox2 ${ }^{+}$cells. $\boldsymbol{C}^{\prime}$, Sox2 was predominantly rescued while Gfi1 rescue was variable. S, Saccule; B, base; Ap, apex; CTL, control. Scale bars, $200 \mu \mathrm{m}$. D, Quantification of Sox $2^{+}$area relative to control showed that only 4\% of the sensory epithelium remained while $24 \%$ of the sensory epithelium was preserved. Students $t$ test; ${ }^{* * *} p<0.00005, n=8$ cochlea per condition. $\boldsymbol{E}$, RT-qPCR analysis on E12.5 + 3 DIV explants confirms that DAPT treatment decreased Sox $2 \mathrm{mRNA}$ expression, while Fgf20 in the presence of DAPT rescued Sox2. Cycle differences to Gapdh with a cutoff at cycle 38. One-way ANOVA for correlated samples show statistical significance; ${ }^{*} p<0.05,{ }^{* *} p<0.01, n=3$ experiments.

crossed to mice that were heterozygous for the Jag1-null allele (The Jackson Laboratory). Male offspring with the genotype Foxg1-Crel ${ }^{+}$; $J a g 1^{\text {null }} /^{+}$were then crossed to homozygous Jag1 flox female mice to generate Jag1 cKO embryos of the genotype Foxg1-Crel ${ }^{+}$; Jag1 $1^{\text {null }} /$ Jag fllox $^{\text {flo }}$ (Kiernan et al., 2006). E14 Jag1 cKO mice were then dissected and probed for Fgf20 transcript by in situ hybridization.

\section{Results}

Fgf20 expression is concomitant with an increase in Sox 2 expression

The temporal and spatial expression of $F g f 20$ is important for cochlear development in the inner ear (see Introduction). We assessed and compared the relative changes of protein levels of Sox 2 by immunolabeling with an antibody to Sox 2 and comparing whole mount explants of similar stages of cochlear development probed for Fgf20 mRNA by in situ hybridization (Fig. 1). There are very low levels of Fgf20 mRNA at E12.5 (Fig. 1A, arrow). Consistent with previous reports, $\mathrm{Fg} 20 \mathrm{mRNA}$ was highly expressed at E13.5 and E14.5 (Fig. $1 B, C$ ). Immunolabeling of
E12.5 explants showed that Sox2 was expressed at low levels (Fig. $\left.1 D, D^{\prime}\right)$. At E13.5, although still weak, there is a marked increase of Sox 2 along the cochlear duct (Fig. $1 E, E^{\prime}$ ). There is a steady and gradual increase of Sox2 from E12.5 to E14.5 that becomes restricted to a well defined stripe along the cochlea by E14.5 (Fig. $1 F, F^{\prime}$ ) that correlated with $F g f 20$ expression in the cochlea (Fig. 1 $\left.A-C, D^{\prime}-F^{\prime}\right)$. Sox 2 expression in the saccule did not correlate with Fgf20 expression, as Fgf20 expression was undetectable in the saccule by in situ hybridization. Gfil was not yet expressed in these early stages of cochlear development (Fig. $1 \mathrm{D}^{\prime}-F^{\prime}$ ), and was first seen in the inner hair cells at E15-E15.5 (data not shown) (Yang et al., 2010).

To confirm the immunohistochemistry and in situ hybridization results with a more quantitative method, we also performed RT-qPCR analysis on E12.5-E18 cochleas with the saccules removed. We analyzed Fgf20 mRNA levels together with Sox2 and an early hair cell marker, Atoh1 (Fig. 1G). We assessed Atoh1 gene expression for hair cell formation, as it is the earliest hair cell 
marker. Fgf20 expression steadily increased from E12.5 to E15.0 and then sharply declined. Sox2 expression also steadily increased from E12.5 to E14.0 and then plateaued. In contrast, the onset of Atoh1 expression began around E14.5, well after the peak expression of $F g f 20$ was attained. Atoh1 expression steadily increased as Fgf20 expression decreased, with a brief period of overlapping expression. RT-qPCR data confirmed the transient expression of Fgf20; however, its expression was more strongly correlated with Sox2 expression than Atoh1 (Fig. $1 G)$.

\section{Notch signaling in the cochlea}

To better understand the relationship between Notch and Fgf20 during early cochlear development, we confirmed the prosensory requirement for Notch signaling in explant cultures (Fig. 2). In E12.5 cochlear explants under control conditions, the sensory epithelium developed in a well organized manner, marked by Sox $2^{+}$and Prox ${ }^{+}$support cells and $\mathrm{Gfil}^{+}$hair cells (Fig. 2A-A"). When treated with DAPT to block Notch signaling, the formation of the prosensory domain was inhibited (Fig. $2 B-B^{\prime \prime}$ ). Both hair cells (Gfil labeled) and support cells (Sox2/Prox1 labeled) were absent after 6 days of DAPT treatment, indicating a complete inhibition of sensory cell formation (Fig. $2 B-B^{\prime \prime}$ ). At later stages of cochlear development, Notch signaling plays a role in lateral inhibition; thus, Notch inhibition with DAPT lead to an increase in hair cell number at the expense of support cells. Control E13.5 explants cultured for 5 days in vitro (DIV) showed even better development, with prominent Prox1 support cell differentiation, in addition to Gfil and Sox2 expression (Fig. 2C, $C^{\prime}$ ). Notch inhibition at E13.5 with DAPT resulted in (1) loss of lateral inhibition in the base to middle regions of the cochlea (Fig. 2D, arrow) and (2) loss of prosensory specification in the apex (Fig. $2 D^{\prime}$ ). At the base, the increase in hair cells was concomitant with a decrease in support cells; as $\mathrm{Gfi}^{+}$cells increase, support cell markers, Sox2 and Prox1, are downregulated (Fig. $2 D, D^{\prime}$ ).

\section{Notch inhibition downregulated $F g f 20$ expression}

To determine whether Fgf20 signaling was downstream of Notch signaling, we explanted E12.5 cochlea and cultured them in the presence or absence of DAPT for 1 DIV. After 1 DIV, Fgf20 mRNA is clearly detectable (Fig. $3 A$ ); however, explants exposed to DAPT showed no Fgf20 mRNA expression (Fig. 3B). We also performed RT-qPCR analysis on E12.5 explants after 3 DIV and observed a loss of Fgf20 expression (Fig. 3C). Three days of Notch inhibition showed the largest decrease in Fgf20 expression, as Fgf20 expression is at peak levels in control E12.5 explants. Control explants reflected a difference in Fgf20 mRNA levels relative to Gapdh of 16.8 cycles. When E12.5 explants were treated with DAPT, Fgf20 mRNA was detectable at cycle number 38 , four cycles after the control samples, indicating no expression of $F g f 20$. We also looked at $\mathrm{Fg} 20$ by in situ hybridization in Jag1 mutants. Consistent with a previous report, Jag1 cKO embryos showed a visible truncation and
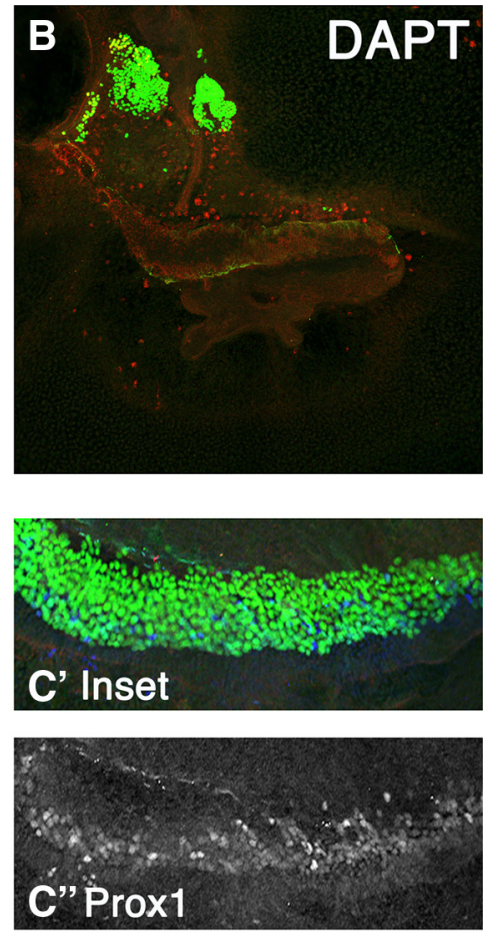

Figure 5. Increasing FGF concentration rescued Prox1 and increased hair cells at E12.5 +6 DIV. $A$, Control E12.5 explants labeled for Gfi1, Sox2, and Prox1. B, DAPT treatment decreased prosensory formation. C, $C^{\prime}$, FGF9 $(1 \mu \mathrm{g} / \mathrm{ml})$ added in the presence of DAPT showed a large increase in hair cell formation. Exogenous FGF9 rescued Prox ${ }^{+}$cells that have not yet completed phenotypic conversion to hair cells, with variable fluorescence intensities (Inset $\boldsymbol{C}^{\prime \prime}$ ).

defects in sensory cell formation (Kiernan et al., 2001). When we compared Jag1 cKO cochleas with wild-type cochleas at the same developmental stage, we found a striking difference. In wildtype embryos, Fgf20 expression is clearly visible at E14 (Fig. 3D); in contrast, Jag1 cKO cochleas have no Fgf20 expression (Fig. 3E). This suggests a requirement of Notch signaling for Fgf20 expression during development. We also saw a decrease in the Jag1 conditional heterozygote (data not shown), suggesting that Fgf20 gene expression may be sensitive to the level of activity of Notch.

\section{FGF20 partially rescued the effects of blocking Notch signaling at E12.5}

Since early prosensory formation and Fgf20 expression were inhibited by DAPT treatment, we hypothesized that the prosensory effects of Notch may be in part mediated through Fgf20 signaling. To test this model, we added exogenous human recombinant FGF20 to E12.5 explants in the presence or absence of DAPT and cultured them for 6 DIV. We excised the roof of the cochlear duct up to the apex to allow maximum exposure of the sensory epithelia to FGF20. Control explants showed normal hair cell and support cell differentiation as seen by the presence of $\mathrm{Gfi}^{+}{ }^{+}$and Sox ${ }^{+}$-labeled cells (Fig. 4A). Prox $1^{+}$-labeled support cells were also present in control explants, indicating normal development of the sensory epithelium (data not shown). Saccules (S) were included to distinguish the base (B) from the apex (Ap) of the cochlea.

DAPT treatment severely affected normal sensory cell formation as evidenced by the absence of support cell and hair cell markers (Fig. 4B). DAPT treatment also disrupted the morphology and shape of the cochlear duct when the duct was opened. To determine the effects on the sensory epithelium and assess the extent of prosensory inhibition, we quantified the total Sox 2 area. Quantification of Sox 2 area showed that only $4 \% \pm 2$ (SEM) of 

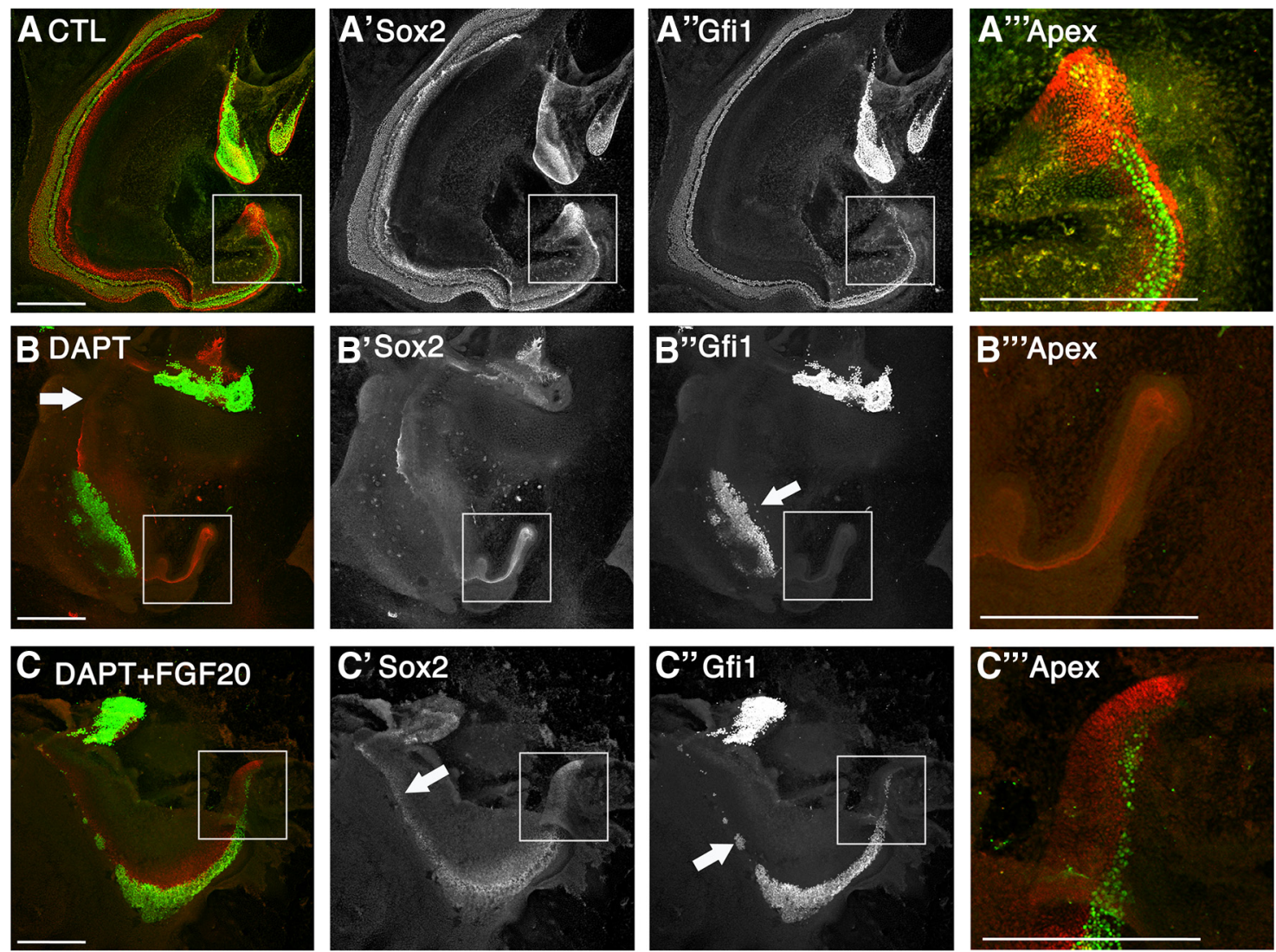

Figure 6. Fgf20 rescued hair cells in addition to Sox2 at E13.5 +5 DIV upon Notch inhibition. $\boldsymbol{A}-\boldsymbol{C}$, Merged images with Gfi1 (green) and Sox2 (red). $\boldsymbol{A}^{\prime}-\boldsymbol{C}^{\prime}$, Sox2 labeling alone. $\boldsymbol{A}^{\prime \prime}-\boldsymbol{C}^{\prime \prime}$, Gfi1 labeling alone. $A^{\prime \prime \prime}-C^{\prime \prime}$, Higher magnification of apices (boxed areas in $\boldsymbol{A}-\boldsymbol{C}$, respectively). $\boldsymbol{A}$, Control E13.5 explants show normal hair cell and support cell development has been completed up to the apex of the cochlea after 5 DIV. $\boldsymbol{B}$, DAPT treatment of E13.5 cochlea revealed both lateral inhibition effects (arrow, $\boldsymbol{B}^{\prime \prime}$ ) and prosensory inhibition at the apex. $\boldsymbol{B}^{\prime}, \boldsymbol{B}^{\prime \prime}$, Sox 2 is downregulated along the whole length of the cochlea while hair cells are formed at the expense of support cells. $\boldsymbol{B}^{\prime \prime \prime}$, No hair cells or support cells were present at the apex. $\boldsymbol{C}$, Fgf20 in the presence of DAPT rescued both $\mathrm{Gfi1}^{+}$hair cells (green) and Sox2 ${ }^{+}$support cells (red). $C^{\prime}$, Sox2 rescue was seen along the whole length of the cochlea. $C^{\prime \prime}, G$ fi1 rescue was seen in the mid-base to apex region of the cochlea with some sporadic rescue in the base. $C^{\prime \prime}$, Both Sox2 and Gfi1 were rescued in the apex of the cochlea. Scale bars- $200 \mu \mathrm{m}$.

the sensory epithelium (Sox2 labeling) remained after DAPT treatment alone relative to controls (Fig. 4D). We collected samples for RT-qPCR after 3 DIV to assess changes in Sox2 mRNA levels during peak $F g f 20$ expression. For all RT-qPCR experiments, saccules were excised. Analysis confirmed that DAPT treatment decreased Sox2 mRNA expression compared to control explants (Fig. 4E). Sox2 mRNA was amplified in control explants at a cycle difference of 13.2 cycles relative to Gapdh. When E12.5 explants were treated with DAPT for 3 DIV, the Sox2 mRNA was amplified five cycles after the control samples, indicating a 32-fold decrease in Sox2 expression relative to controls.

In contrast, when FGF20 was added to DAPT-treated cultures, we saw a partial rescue in cochlear development. Immunolabeling showed a rescue of Sox ${ }^{+}$cells relative to DAPT-treated explants alone (Fig. 4C). Upon quantifying the Sox2 area, we saw an increase by $24 \% \pm 4$ (SEM) (Fig. $4 D$ ). RT-qPCR analysis confirmed a significant rescue of Sox2 transcript levels in explants treated with FGF20 and DAPT versus DAPT-treated explants alone (Fig. 4E). Sox2 mRNA levels increased by three cycles (8fold increase) relative to cochlear explants treated with DAPT alone. RT-qPCR analysis also showed a decrease in Pea3 mRNA, a known transcription factor downstream of FGF signaling, upon DAPT treatment. Addition of FGF20 in the presence of DAPT also rescued Pea3 mRNA levels (data not shown). The extent of rescue of hair cells as evidenced by $\mathrm{Gfil}^{+}$labeled cells was variable from explant to explant; however, the presence of isolated patches of hair cells suggests that rescued sensory cells have a potential to further differentiate into hair cells (Fig. $4 C^{\prime}$ ). One of eight explants showed a dramatic increase in hair cells (data not shown). These data support the hypothesis that the prosensory effect of Notch signaling is mediated at least in part through Fgf20.

FGF9 is in the same subfamily as FGF20 and can rescue hair cell formation in the Fgf20 knockout (Huh et al., 2012). Moreover, FGF9 shows similar but stronger biochemical activity to FGF20. We therefore also tested FGF9 for its potential to rescue prosensory specification in the presence of DAPT (Fig. 5). Control explants showed differentiation of all the major sensory cell markers, Sox2, Gfil, and Prox1 (Fig. 5A), when E12.5 were cultured for 6 days (6 DIV). In the presence of DAPT, we saw no prosensory formation (Fig. $5 B$ ). When we added FGF9 in the presence of DAPT, there was an even greater rescue of hair cell formation than that which occurred with FGF20 (Fig. $5 C, C^{\prime}$ ). Since DAPT remained in the media for the entire duration of the culture period, this increase occurred at the expense of Sox 2 and Prox 1 cells. However, we did see a few Prox1-positive cells along the length of the cochlea (Fig. $5 C^{\prime \prime}$ ). Therefore, at higher concentrations of FGF we saw an increase in $\mathrm{Gfil}^{+}$cells and a rescue of Prox ${ }^{+}$cells, while at lower concentrations only Sox $2^{+}$cells were predominantly rescued (Fig. 4).

\section{FGF20 partially rescued the prosensory effects of Notch} inhibition at E13.5

Cochleas at E13.5 continue to require the prosensory Notch signal at the apex (Fig. 2D'). Control explants show that support cell and hair cell differentiation progressed along the entire length of 
the duct up to the apex after 5 days (Fig. $\left.6 A-A^{\prime \prime \prime}\right)$. Notch inhibition in E13.5 explants showed a block in both lateral inhibition and prosensory formation in a spatially dependent manner (Fig. $6 B)$. The mid-cochlear region showed a block in lateral inhibition, resulting in an increase of Gfi1 ${ }^{+}$labeled hair cells (Fig. $6^{\prime \prime}$, arrow) that formed at the expense of the Sox $2^{+}$support cells (Fig. $\left.6 B^{\prime}\right)$. In addition, the apical end of the cochlea exhibits prosensory inhibition where both the formation of support cells and hair cells were affected (Fig. $6 B$ inset, $B^{\prime \prime \prime}$ ).

Addition of FGF20 in the presence of DAPT rescued hair cells in the apical portion of the cochlea (Fig. $6 C$ inset, $C^{\prime \prime \prime}$ ). We quantified the number of hair cells in the apical region. To quantify the rescue of hair cells in the apical region, the cochlear duct was divided into four portions and the total number of hair cells in the apical $25 \%$ of the duct was counted (Fig. 7A). The total number of hair cells found in the apex of controls was $236 \pm 38$ (SEM). DAPT-treated cochlea contained only $24 \pm 12$ (SEM) hair cells. Addition of FGF20 with DAPT significantly increased the total number of hair cells at the apex to $146 \pm 16$ (SEM) (Fig. 7A). Therefore, FGF20 was able to rescue DAPT-mediated hair cell inhibition at the apex. However, Notch inhibition with DAPT also resulted in a truncated cochlear duct (Fig. 7B). At E13.5, the cochlear ducts were still discernable and duct lengths were measured based on their morphological features. The average length of cochlear ducts in control explants was $2143 \mu \mathrm{m} \pm 110$ (SEM), while DAPT treatment significantly truncated the duct to 1836 $\mu \mathrm{m} \pm 77$ (SEM). Addition of FGF20 in the presence of DAPT did not increase the length of the duct relative to DAPT treatment alone (Fig. 7B). Therefore, we counted all the hair cells in the apical $25 \%$ of the duct and normalized them to the length of the apical region (hair cells $/ 100 \mu \mathrm{m}$ ). Controls consisted of $44 \pm 5$ hair cells per $100 \mu \mathrm{m}$ in the apex. DAPT treatment decreased this to $6 \pm 2$ hair cells, while FGF20 increased hair cell numbers much more significantly to $33 \pm 3$ hair cells per $100 \mu \mathrm{m}$ in the apex (Fig. 7C). Addition of FGF20 to DAPT-treated cultures also increased the length and the area of the Sox ${ }^{+}$labeled sensory epithelium (Fig. 6C). We quantified the percentage of the sensory epithelium that spanned the length of the duct by measuring the length of sensory epithelium (Sox2 labeling) relative to total duct length. In controls, Sox $2^{+}$cells spanned the entire length of the duct, suggesting that $97.9 \% \pm 0.6$ (SEM) of the duct therefore contained Sox 2 labeling; nearly the entire duct consisted of cells that are Sox ${ }^{+}$. Upon DAPT treatment, only $46.0 \% \pm 6.8$ of the duct contained Sox $2^{+}$cells. When FGF20 was supplemented, $84.8 \% \pm 3.5$ of the duct was Sox2 labeled (Fig. 7D). Next, we assessed overall changes in the area of total sensory epithelium upon DAPT treatment in the presence and absence of FGF20 (including both regions of lateral inhibition and prosensory effects). DAPT treatment alone resulted in a decrease in the area of the sensory epithelium to $35 \% \pm 9.5$ (SEM) relative to control explants. Addition of FGF20 along with DAPT rescued the total area of the sensory epithelium to $69 \% \pm 12$ (SEM), suggesting there was an increase in prosensory formation in all regions of the cochlea (Fig. $7 E$ and Fig. $6 C^{\prime}$, arrow).

Rescue of hair cells at the basal portion of the cochlea was seen in some explants and was absent in others, while hair cells were consistently rescued at the apex. Although it is important to note that Notch inhibition was equally inconsistent in blocking lateral inhibition at the very base of the cochlea and occasionally blocked prosensory formation instead (Fig. $2 D$, arrow and $5 B$, arrow). These differences likely depend on the exact age of the individual explant. Occasionally, we observed patches of hair cells in the basal portion of the cochlear duct in the presence of FGF20 and
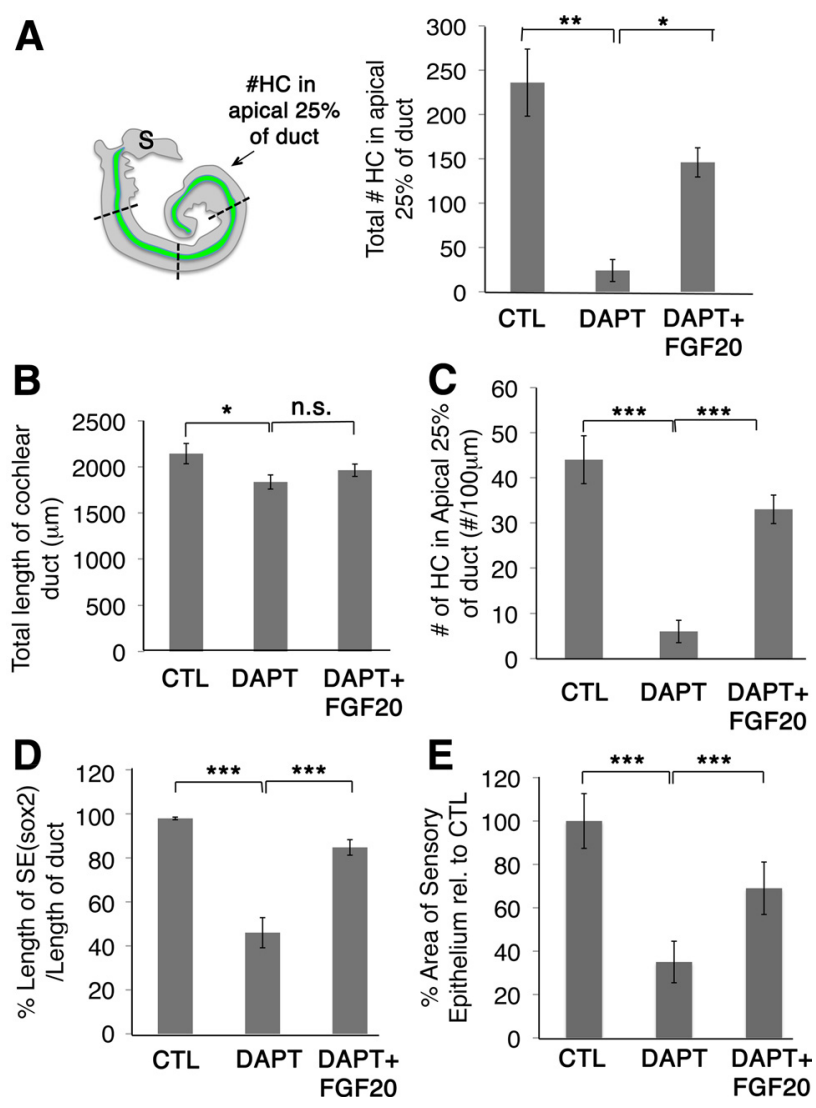

Figure 7. Quantification of FGF20 rescue effects. $A$, Each cochlea was divided into four regions by length. Total number of hair cells (\#HC) was counted in the apical $25 \%$ of the duct; control (CTL), $n=8 ;$ DAPT, $n=9 ;$ FGF20 + DAPT, $n=10$. Controls consisted of $236 \pm 38$ hair cells in the apex; DAPT treatment decreased the total hair cell number to $24 \pm 12$ while adding FGF20-rescued total hair cell numbers to $146 \pm 16$ in the apex. S, Saccule. $\boldsymbol{B}$, DAPT treatment truncated the cochlear duct. Duct lengths were measured from base to apex based on morphological features of the cochlea. The average length of cochlear ducts of control explants was $2143 \mu \mathrm{m} \pm 110$ (SEM), while DAPT treatment significantly truncated the duct to $1836 \mu \mathrm{m} \pm$ 77 (SEM); CTL, $n=14 ;$ DAPT, $n=15 ;$ FGF20 + DAPT, $n=16$. C, Hair cells were also counted in the apical $25 \%$ of the duct, taking into account the length of the duct, and we show the number of hair cells per $100 \mu \mathrm{m}$. Controls consisted of $44 \pm 5$ hair cells per $100 \mu \mathrm{m}$ in the apex. DAPT treatment decreased this to $6 \pm 2$ hair cells, while Fgf 20 rescued $33 \pm 3$ hair cells per 100 $\mu \mathrm{m}$ in the apex; CTL, $n=8 ; \mathrm{DAPT}, n=9 ; \mathrm{FGF} 20+$ DAPT $n=10 . \boldsymbol{D}$, The length of the sensory epithelium (SE), labeled by Sox2, was normalized to the length of the duct. In controls, Sox2 labeling spans the entire length of the duct, resulting in a value of $97.9 \% \pm 0.6$ (SEM). Upon DAPT treatment, only $46.0 \% \pm 6.8$ of the duct was spanned by Sox 2 labeling. When FGF20 was supplemented, $84.8 \% \pm 3.5$ of the duct was spanned; CTL $n=14$, DAPT $n=15$, FGF20 + DAPT, $n=16$. $E$, Since Sox 2 was downregulated upon DAPT treatment, we measured the area of the sensory epithelium by quantifying the total area occupied by Sox2 ${ }^{+}$and $\mathrm{Gfi}^{+}$cells. DAPT treatment also decreased the area of the sensory epithelium to $35 \% \pm 9.5$ (SEM) relative to control explants. Adding Fgf20 along with DAPT rescued the total area of the sensory epithelium to $69 \% \pm 12$ (SEM); CTL $n=14$, DAPT $n=15$, FGF20 + DAPT $n=16$. Student's $t$ test ${ }^{*} p<$ $0.05,{ }^{* *} p<0.0005,{ }^{* * *} p<0.00005$, n.s., Not significant.

DAPT (Fig. $6 C^{\prime \prime}$, arrow). Sox $2^{+}$cells were rescued almost along the entire length of the duct (Fig. $6 C^{\prime}$, arrow).

\section{Discussion}

In this report, we have provided new insight into the relationship between the Notch and FGF pathways during prosensory induction in the cochlea. (1) we showed that the expression of $F g f 20$ is dependent on Notch signaling. At the time of prosensory induction, Notch inhibition led to a decline in Fgf20 expression, as shown by RT-qPCR and in situ hybridization. Jag1 cKO mutants also showed a loss of $F g 20$ expression. (2) In addition, we found 


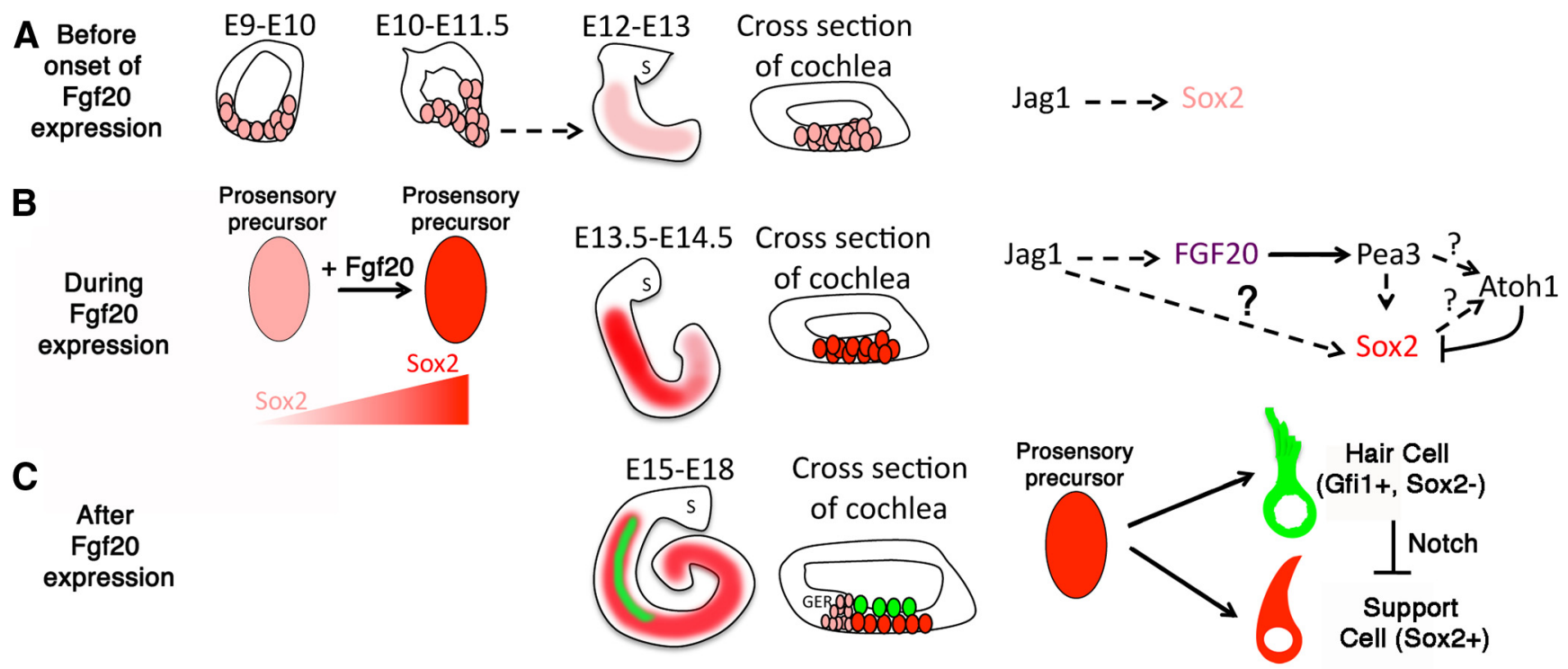

Figure 8. Model of Fgf20 function during development. $A$, Sox2 is expressed in the developing otocyst and is downstream of Notch signaling. Before Fgf20 expression, Sox2 levels are low as cochlear elongation occurs. B, Fgf20 expression acts downstream of Notch signaling and sweeps in a base to apex manner from E13.5 to E14.5. We hypothesize that Fgf20 is spatially expressed in the sensory domain and increases Sox2 expression to specify prosensory precursors in the developing cochlea. C, Fgf20 expression is transient and downregulates around E15. When Sox2 expression reaches a critical level in prosensory progenitors, they are able to differentiate into hair cells and support cells. S, Saccule; GER, greater epithelial ridge.

that FGF20 can rescue the inhibition of Notch in explant cultures. FGF20 added to E12.5 explants rescues Sox2 expression and in some cases sensory cells, while FGF9, a more potent member of the FGF20 subfamily, can rescue a substantial number of sensory cells in the presence of continuous Notch inhibition with DAPT. Also, FGF20 added to DAPT-treated E13.5 explants provides a consistent rescue of sensory cells in the apex. Together, these results support a model in which prosensory specification by Notch signaling acts at least in part via regulation of Fgf20 expression and function.

Although we found that FGF20 can rescue the block in sensory cell development caused by inhibition of Notch at both E12.5 and E13.5, very few hair cells were rescued in the E12.5 explants (Fig. 4). Only one of eight explants showed a dramatic increase in hair cells, while the rest showed a predominant rescue of Sox ${ }^{+}$cells. By contrast, in E13.5 cultures DAPT treatment inhibits hair cell and support cell formation in the apex, and co-treatment with FGF20 rescued both (Fig. 6). This difference may be attributed to the age of cochleas at the time of explant and the timing of Fof 20 expression. Significant $\mathrm{F} g \mathrm{f} 20$ expression was already initiated at E13.5 (Fig. 1B). In this scenario, DAPT treatment would only downregulate Fgf20 expression after exposure to DAPT; thus, we may be seeing an additive effect of endogenous Fgf20 that was already expressed in addition to the exogenous FGF20, rescuing both $\mathrm{Gfil}^{+}$hair cells and Sox $2^{+}$support cells (Fig. $\left.6 C^{\prime \prime}\right)$. If an additive effect of FGF was responsible for differentiation of hair cells and support cells, we expect that increasing the concentration of FGF would also increase hair cells. When we added FGF9, instead of FGF20, to the E12.5 cultures in the presence of DAPT, we saw a dramatic rescue in the number of hair cells (Fig. 5). Since FGF9 is related to FGF20 but is more active when produced in recombinant form on the same receptors (Huh et al., 2012), the fact that it can rescue DAPT-treated E12.5 sensory cell development suggests that the lack of efficient rescue with FGF20 at E12.5 is most likely a technical issue with the protein. We also observed a few Prox $1^{+}$cells with FGF9, some of which were in the midst of undergoing transdifferentiation due to DAPT. Thus, a higher FGF concentration pushed cells to differentiate. This supports the hypothesis that a critical level of Sox2 is required for the initiation of Atoh1 expression.

Previous reports have shown that $F g f 20$ is required for auditory development (Hayashi et al., 2008b; Huh et al., 2012) and activates Fgfrl to regulate sensory cell formation (Pirvola et al., 2002; Hayashi et al., 2008b). In vitro studies with the FGF receptor inhibitor SU5402 showed a decrease in Sox ${ }^{+}$cells and hair cells. In these in vitro studies all FGF receptors were pharmacologically inhibited, thus excluding the possibility of compensation by other FGFs expressed in the cochlea, namely Fgf9, Fgf8, Fgf10, and Fgf16 (Pirvola et al., 2002, 2004; Pauley et al., 2003; Hatch et al., 2009). It is noteworthy, then, that although FGF20 is required for sensory cell formation, it is not sufficient. When we cultured both E12.5 and E14.5 explants with FGF20 alone, there was no obvious increase in hair cell numbers or any ectopic hair cell formation (data not shown). This observation was consistent with a recent report in which exogenous FGF9 also did not increase hair cell numbers during sensory development in normal explants (Huh et al., 2012). Therefore, the region of the cochlear duct competent to generate sensory cells appears to be limited by some other factors, for example a negative feedback mechanism that inactivates excessive FGF receptor signaling, potentially via Spry2, an inhibitor of FGF signaling (Shim et al., 2005).

How does Notch signaling regulate Fgf20? It is possible that Fgf20 is directly downstream of the prosensory Notch signal, since a putative Rbpj binding site exists in the Fgf2O promoter region. Previous studies have shown that in the developing cochlea, Sox2 expression is downstream of Notch signaling. Jag1 cKO mice showed a reduction in Sox2 expression, and overexpression of NICD induced Sox 2 expression in chicks and mice (Kiernan et al., 2006; Dabdoub et al., 2008; Hartman et al., 2010; Pan et al., 2010). Both Notch and Sox 2 are required for the regulation of this prosensory domain (Kiernan et al., 2005a, 2006). Moreover, we previously reported that $F g 20$ was expressed within the Sox 2 domain (Hayashi et al., 2008b). Nevertheless, the regulation of Sox2 is likely to be complex, since it is also clear that FGFs can promote Sox2 expression. Evidence presented in this report shows that FGF20 can rescue Sox2 expression in the ab- 
sence of the prosensory Notch signal, and the presence of several Pea3 binding sites on the Sox2 promoter suggest this regulation could be direct. In addition, the early Sox 2 domain in Xenopus explants appears to be partially specified by FGF signaling; when embryos were treated with SU5402, Sox2 expression decreased (Wills et al., 2010). Also, FGFs promote sensory competence in zebrafish (Sweet et al., 2011). We show that Fgf20 could temporally act as an intermediate player in the Notch-Sox2 pathway.

These data support a model in which Fgf20 is downstream of the Notch-induced prosensory signal. We propose that Notch signaling activates Fgf20 expression in the prosensory domain, and this activates Fgfr1 to increase Sox2 expression to a critical level to specify prosensory cells. The prosensory cells will then differentiate into hair cells and mature support cells (Fig. 8). We posited that while low Sox2 levels are already present before $F g f 20$ expression (Fig. $8 A$ ), Fgf20 upregulates Sox 2 expression to a critical level (Fig. $8 B$ ). Recent findings in other systems, such as the mouse eye and neocortex, show that Sox2 is expressed at a low level before the expression of Jag1 or Notch signaling and regulates Notch expression (BaniYaghoub et al., 2006; Taranova et al., 2006). In the developing otic placode, Sox2 is present as early as E8 (Wood and Episkopou, 1999). While it has been shown that Sox2 antagonizes Atoh1 expression (Dabdoub et al., 2008), recent evidence shows the presence of Sox2 transcription activation sites on the Atohl promoter region (Neves et al., 2011). Fgf20 expression is high between the ages of E13 and E15 in the cochlea (Hayashi et al., 2008b). While Sox2 expression occurs early in otic development, Fgf20 appears to be required for increasing Sox 2 expression or maintaining expression in progenitors. When Fgf20 levels (or Sox2) reach a critical level of expression, these progenitors proceed to adopt either a hair cell fate or a support cell fate (Fig. 8C). While we showed rescue of Gfil ${ }^{+}$and Prox ${ }^{+}$cells, there is stronger precedence for Fgf20's role in prosensory formation. In addition, Fgf20 was found to be essential for fin regeneration in zebrafish (Whitehead et al., 2005). Thus, Fgf20 remains to be an attractive therapeutic for the regeneration of prosensory cells in the damaged cochlea.

\section{References}

Bani-Yaghoub M, Tremblay RG, Lei JX, Zhang D, Zurakowski B, Sandhu JK, Smith B, Ribecco-Lutkiewicz M, Kennedy J, Walker PR, Sikorska M (2006) Role of Sox 2 in the development of the mouse neocortex. Dev Biol 295:52-66.

Brooker R, Hozumi K, Lewis J (2006) Notch ligands with contrasting functions: Jagged1 and Delta1 in the mouse inner ear. Development 133:1277-1286.

Chen P, Segil N (1999) p27(Kip1) links cell proliferation to morphogenesis in the developing organ of Corti. Development 126:1581-1590.

Dabdoub A, Puligilla C, Jones JM, Fritzsch B, Cheah KS, Pevny LH, Kelley MW (2008) Sox2 signaling in prosensory domain specification and subsequent hair cell differentiation in the developing cochlea. Proc Natl Acad Sci U S A 105:18396-18401.

Daudet N, Lewis J (2005) Two contrasting roles for Notch activity in chick inner ear development: specification of prosensory patches and lateral inhibition of hair-cell differentiation. Development 132:541-551.

Daudet N, Ariza-McNaughton L, Lewis J (2007) Notch signalling is needed to maintain, but not to initiate, the formation of prosensory patches in the chick inner ear. Development 134:2369-2378.

Hartman BH, Reh TA, Bermingham-McDonogh O (2010) Notch signaling specifies prosensory domains via lateral induction in the developing mammalian inner ear. Proc Natl Acad Sci U S A 107:15792-15797.

Hatch EP, Urness LD, Mansour SL (2009) Fgf16(IRESCre) mice: a tool to inactivate genes expressed in inner ear cristae and spiral prominence epithelium. Dev Dyn 238:358-366.

Hayashi T, Kokubo H, Hartman BH, Ray CA, Reh TA, BerminghamMcDonogh O (2008a) Hesr1 and Hesr2 may act as early effectors of Notch signaling in the developing cochlea. Dev Biol 316:87-99.

Hayashi T, Ray CA, Bermingham-McDonogh O (2008b) Fgf20 is required for sensory epithelial specification in the developing cochlea. J Neurosci 28:5991-5999.

Hayashi T, Ray CA, Younkins C, Bermingham-McDonogh O (2010) Expression patterns of FGF receptors in the developing mammalian cochlea. Dev Dyn 239:1019-1026.

Huh SH, Jones J, Warchol ME, Ornitz DM (2012) Differentiation of the lateral compartment of the cochlea requires a temporally restricted FGF20 signal. PLoS Biol 10:e1001231.

Kiernan AE, Ahituv N, Fuchs H, Balling R, Avraham KB, Steel KP, Hrabé de Angelis M (2001) The Notch ligand Jagged1 is required for inner ear sensory development. Proc Natl Acad Sci U S A 98:3873-3878.

Kiernan AE, Pelling AL, Leung KK, Tang AS, Bell DM, Tease C, Lovell-Badge $\mathrm{R}$, Steel KP, Cheah KS (2005a) Sox2 is required for sensory organ development in the mammalian inner ear. Nature 434:1031-1035.

Kiernan AE, Cordes R, Kopan R, Gossler A, Gridley T (2005b) The Notch ligands DLL1 and JAG2 act synergistically to regulate hair cell development in the mammalian inner ear. Development 132:4353-4362.

Kiernan AE, Xu J, Gridley T (2006) The Notch ligand JAG1 is required for sensory progenitor development in the mammalian inner ear. PLoS Genet 2:e4.

Lim DJ, Anniko M (1985) Developmental morphology of the mouse inner ear. A scanning electron microscopic observation. Acta Otolaryngol Suppl 422:1-69.

Millimaki BB, Sweet EM, Riley BB (2010) Sox2 is required for maintenance and regeneration, but not initial development, of hair cells in the zebrafish inner ear. Dev Biol 338:262-269.

Neves J, Parada C, Chamizo M, Giráldez F (2011) Jagged 1 regulates the restriction of Sox2 expression in the developing chicken inner ear: a mechanism for sensory organ specification. Development 138:735-744.

Pan W, Jin Y, Stanger B, Kiernan AE (2010) Notch signaling is required for the generation of hair cells and supporting cells in the mammalian inner ear. Proc Natl Acad Sci U S A 107:15798-15803.

Pauley S, Wright TJ, Pirvola U, Ornitz D, Beisel K, Fritzsch B (2003) Expression and function of FGF10 in mammalian inner ear development. Dev Dyn 227:203-215.

Pirvola U, Ylikoski J, Trokovic R, Hébert JM, McConnell SK, Partanen J (2002) FGFR1 is required for the development of the auditory sensory epithelium. Neuron 35:671-680.

Pirvola U, Zhang X, Mantela J, Ornitz DM, Ylikoski J (2004) Fgf9 signaling regulates inner ear morphogenesis through epithelial-mesenchymal interactions. Dev Biol 273:350-360.

Ruben RJ (1967) Development of the inner ear of the mouse: a radioautographic study of terminal mitoses. Acta Otolaryngol Suppl 220:221-244.

Sher AE (1971) The embryonic and postnatal development of the inner ear of the mouse. Acta Otolaryngol Suppl 285:1-77.

Shim K, Minowada G, Coling DE, Martin GR (2005) Sprouty2, a mouse deafness gene, regulates cell fate decisions in the auditory sensory epithelium by antagonizing FGF signaling. Dev Cell 8:553-564.

Sweet EM, Vemaraju S, Riley BB (2011) Sox2 and Fgf interact with Atoh1 to promote sensory competence throughout the zebrafish inner ear. Dev Biol 358:113-121.

Taranova OV, Magness ST, Fagan BM, Wu Y, Surzenko N, Hutton SR, Pevny LH (2006) SOX2 is a dose-dependent regulator of retinal neural progenitor competence. Genes Dev 20:1187-1202.

Theiler K (1989) The house mouse: atlas of embryonic development, Ed 2. New York: Springer.

Whitehead GG, Makino S, Lien CL, Keating MT (2005) fgf20 is essential for initiating zebrafish fin regeneration. Science 310:1957-1960.

Wills AE, Choi VM, Bennett MJ, Khokha MK, Harland RM (2010) BMP antagonists and FGF signaling contribute to different domains of the neural plate in Xenopus. Dev Biol 337:335-350.

Wood HB, Episkopou V (1999) Comparative expression of the mouse Sox1, Sox2 and Sox3 genes from pre-gastrulation to early somite stages. Mech Dev 86:197-201.

Yamamoto N, Chang W, Kelley MW (2011) Rbpj regulates development of prosensory cells in the mammalian inner ear. Dev Biol 353:367-379.

Yang H, Gan J, Xie X, Deng M, Feng L, Chen X, Gao Z, Gan L (2010) Gfil-Cre knock-in mouse line: A tool for inner ear hair cell-specific gene deletion. Genesis 48:400-406.

Zine A, Aubert A, Qiu J, Therianos S, Guillemot F, Kageyama R, de Ribaupierre F (2001) Hes1 and Hes5 activities are required for the normal development of the hair cells in the mammalian inner ear. J Neurosci 21:4712-4720. 